\title{
Impact of the 2014 coinsurance rate revision for the elderly on healthcare resource utilization in Japan
}

\author{
Takumi Nishi $^{1 *} \mathbb{D}$, Toshiki Maeda ${ }^{2}$, Susumu Katsuki ${ }^{1}$ and Akira Babazono ${ }^{3}$
}

\begin{abstract}
Background: Cost sharing, including copayment and coinsurance, is often used to contain medical expenditure by decreasing unnecessary or excessive use of healthcare resources. Previous studies in Japan have reported the effects of a coinsurance rate reduction for healthcare from 30 to $10 \%$ on the demand for healthcare among 70-74year-old individuals. However, the coinsurance rate for this age group has recently increased from 10 to $20 \%$. This study aimed to estimate the economic impact of coinsurance rate revision on healthcare resource utilization.
\end{abstract}

Methods: We collected claims data from beneficiaries of the municipality National Health Insurance and the Japanese Health Insurance Association in Fukuoka Prefecture. We categorized subjects born between March 2, 1944 and April 1, 1944 into the 20\% coinsurance rate reduction group and those born between April 2, 1944 and May 1, 1944 into the 10\% reduction group. An interrupted time-series analysis for multiple groups was employed to compare healthcare resource utilization trends before and after coinsurance rate reduction at 70 years.

Results: The 10\% coinsurance rate reduction led to a significant increase in healthcare expenditure for outpatient care. The 20\% reduction group showed a significantly sharper increase in healthcare expenditure for outpatient care than the 10\% reduction group. Similarly, the $10 \%$ coinsurance group significantly increased in the number of ambulatory visits. The $20 \%$ coinsurance rate reduction group had more frequent ambulatory care visits than the $10 \%$ reduction group.

Conclusions: These results suggest that increasing the coinsurance rate among the elderly would reduce outpatient healthcare resource utilization; however, it would not necessarily reduce overall healthcare resource utilization.

Keywords: Elderly, Health, Health insurance, Medical care, Public health

\section{Background}

Similar to other developed countries, Japan has a rapidly aging population. In $2020,36.17$ million people $(28.7 \%$ of the total population) were aged 65 years or older [1]. One estimate suggests that the number and proportion of such older people will increase to 39.21 million

\footnotetext{
* Correspondence: nishi@fihes.pref.fukuoka.jp

${ }^{1}$ Department of Research Planning and Information Management, Fukuoka Institute of Health and Environmental Sciences, 39 Mukaizano, Dazaifu-shi, Fukuoka 818-0135, Japan

Full list of author information is available at the end of the article
}

(35.3\%) in fiscal year (FY) 2040. Social security expenditure in Japan is expected to rapidly increase from approximately 121.3 trillion yen (21.5\% of GDP) in FY 2018 to about $188.2-190.0$ trillion yen $(23.8-24.0 \%$ of GDP) in FY 2040 [2].

Higher patient cost sharing is often used to contain medical expenditure by reducing unnecessary or excessive use of healthcare resources. Using results from the famous RAND Health Insurance Experiment (RHIE) in 1974, Manning et al. examined cost-sharing effects on 
the demand for medical services and reported that price elasticity was approximately -0.2 . However, individuals aged 62 years or older at enrollment were intentionally excluded as ineligible groups in the RHIE [3]. Thereafter, Chandra et al. studied a policy change that raised patient cost sharing for supplemental insurers for retired public employees, including the elderly in California, and reported that elasticity for ambulatory care and prescription drugs was similar to that of RHIE [4]. However, these studies evaluated the effects of basic or supplemental insurance provision rather than patient cost sharing.

Patient cost sharing should be examined especially in rapidly aging countries, such as Japan, where among 43.07 trillion yen of national healthcare expenditure in FY 2017, 25.95 trillion yen (60.3\%) was consumed by the elderly aged 65 years or older [5]. Nevertheless, little was known about the effects of cost sharing on healthcare utilization among the elderly, until few recent few studies in Japan. First, Shigeoka exploited a sharp reduction in patient cost sharing at age 70 in Japan by using patient survey data, death records, and the Comprehensive Survey of Living Conditions [6]. Fukushima et al. examined the effects of reducing the coinsurance rate from 30 to $10 \%$ for medical care on demand among Japanese people aged 70 years and older by analyzing claims data from health insurance societies [7]. These studies reported that both outpatient and inpatient care were price sensitive among the elderly. Further, considering the coinsurance rate revision for Japanese people aged 70-74 years, Mahlich and Sruamsiri evaluated the impact of increased coinsurance rates on drug, inpatient, and outpatient healthcare utilization among Japanese elderly with rheumatoid arthritis by analyzing administrative data from 147 acute care hospitals [8].

However, the overall situation remains unclear after the coinsurance rate revision for elderly people aged 7074 years in 2014 for the following reasons. First, data analyzed by Shigeoka did not contain information about healthcare expenditure other than self-reported out-ofpocket medical spending [6]. Second, the study subjects of Fukushima et al. did not include beneficiaries of national health insurance (NHI), which is the most popular insurer for people aged 65-74 years in Japan [7]. Both evaluated the effects of reducing the coinsurance rate from 30 to $10 \%$ for medical care on demand among Japanese aged 70-74 years, but not after the coinsurance rate revision in 2014. Moreover, the study conducted by Mahlich and Sruamsiri did not include patients with medical conditions other than rheumatoid arthritis and medical institutions other than acute care hospitals [8].

Therefore, determining the effects of the coinsurance rate revision by comparison with the previous coinsurance rate would have important policy implications in healthcare economics. In this study, we estimated the economic impacts of the coinsurance rate revision on healthcare resource utilization by analyzing longitudinal health insurance claims data. Further, although previous studies implemented age-based regression discontinuity design, we employed interrupted time-series analysis (ITSA), which is a useful quasi-experimental design for evaluating the longitudinal effects of the coinsurance rate revision. As a result, we found that the coinsurance reduction from 30 to $20 \%$ also increased the utilization of outpatient healthcare resources, although its impact was smaller than with a $20 \%$ reduction.

\section{Institutional setting}

In Japan, since universal health coverage was achieved in 1961, almost every person is covered by public health insurance. Although several types of insurers are available in Japan, such as NHI, Japanese health insurance association (JHIA), health insurance societies, mutual aid associations, and medical care systems for the elderly in the later stages of life, medical service fees are reimbursed based on a nationally uniform fee schedule. Many outpatient and inpatient services were reimbursed by fees for service schemes; however, in 2003, a prospective payment system for acute inpatient services was introduced. The diagnosis procedure combination per diem payment system (DPC/PDPS) is a prospective payment system applied on a per diem basis and covers about $54 \%$ of general hospital beds. The prices of prescription drugs and specific medical devices were also regulated nationally through uniform price lists.

Beneficiaries have free access to each type of medical institution authorized for providing medical, dental, and pharmaceutical services covered by health insurance. However, additional copayment is required for the first visit to a large hospital without a physician's referral. Moreover, other than catastrophic coverage, patient bill copayment at medical institutions and the rest of the fees would be reimbursed by insurers.

\section{Cost-sharing reforms in Japan}

The Japanese government implemented several costsharing reforms. First, copayments (inpatients, 300 yen/ day; outpatients, 400 yen/day) for the elderly aged 65 years or older were introduced in February 1983; however, these individuals did not have to pay out-of-pocket expenses from January 1973 until February 1983. Subsequently, with the reform of Japan's health insurance system in January 2001, 10\% coinsurance was introduced. Then, coinsurance rate for the elderly with high income which is comparable to the current workforce was increased to $20 \%$ in October 2002, and it was increased to $30 \%$ in October 2006. Further, owing to a rapid increase in medical expenditure for older people, in 2008, the 
government implemented an independent health insurance system for individuals aged 75 years or older as part of the medical care system for the elderly in the latter stage of life. Accordingly, the coinsurance rate for people in Japan aged 70-74 years increased from 10 to $20 \%$, after the amendment of the Health Insurance Act and National Health Insurance Act $[9,10]$. To mitigate the impact of rapid change, the coinsurance rate was frozen at $10 \%$ except by budgetary provision after 2008 . However, the $20 \%$ coinsurance rate was enforced for people who reached 70 years of age after April 2014 to reduce inequity across generations. Therefore, since FY2014, the coinsurance rate for people who reached 70 years of age (i.e., those who were born after April 2, 1944) decreased from $30 \%$ (for people aged 6-69 years of age) to $20 \%$ (for people aged 70-74 years of age) after their birth month, while the coinsurance rate for people who had already reached 70 years of age (i.e., those who were born before April 1, 1944) decreased from 30 to $10 \%$.

\section{Data}

The data of health insurance beneficiaries aged 70 years in FY 2013 or 2014 and their health insurance claims data other than that of dental care were obtained from the claims database of municipality NHI in Fukuoka Prefecture and the Fukuoka branch of the JHIA. We collected claims data before and after 12 months from the next month of the 70th birthdays of 16,353 beneficiaries who were born between March 2, 1944 and May 1, 1944. Figure 1 presents the inclusion and exclusion criteria and the subject selection flow chart. First, we excluded 8194 individuals who obtained or lost quantification for health insurance the year before or after their birthday. Further, we excluded 955 beneficiaries with income comparable to the current workforce, that is, those who did not change their coinsurance rates. Finally, 7205 beneficiaries were selected as study subjects. We categorized subjects born between March 2, 1944 and April 1, 1944 and whose coinsurance rates were to decrease to $10 \%$ the following month upon reaching 70 years of age into the $20 \%$ (coinsurance rates) reduction group. We classified those born between April 2, 1944 and May 1, 1944 and those whose insurance rates decreased to $20 \%$ into the $10 \%$ reduction group.

Moreover, health insurance beneficiaries can receive catastrophic coverage, as shown in Table 1. As catastrophic coverage was delivered in kind for beneficiaries who presented the "Eligibility Certificate for CeilingAmount Application" or an "Eligibility Certificate for Ceiling-Amount Application and Reduction of the Standard Amount of Patient Liability," we computed actual out-of-pocket payments by using information on out-of-pocket payments for catastrophic coverage. Subsequently, we calculated the actual coinsurance rate, dividing this by total healthcare expenditure. The actual coinsurance rates of the $10 \%$ reduction group before and after 70 years of age were 23.5 and $13.1 \%$ in overall settings, 29.5 and $18.0 \%$ for outpatient care, and 11.7 and

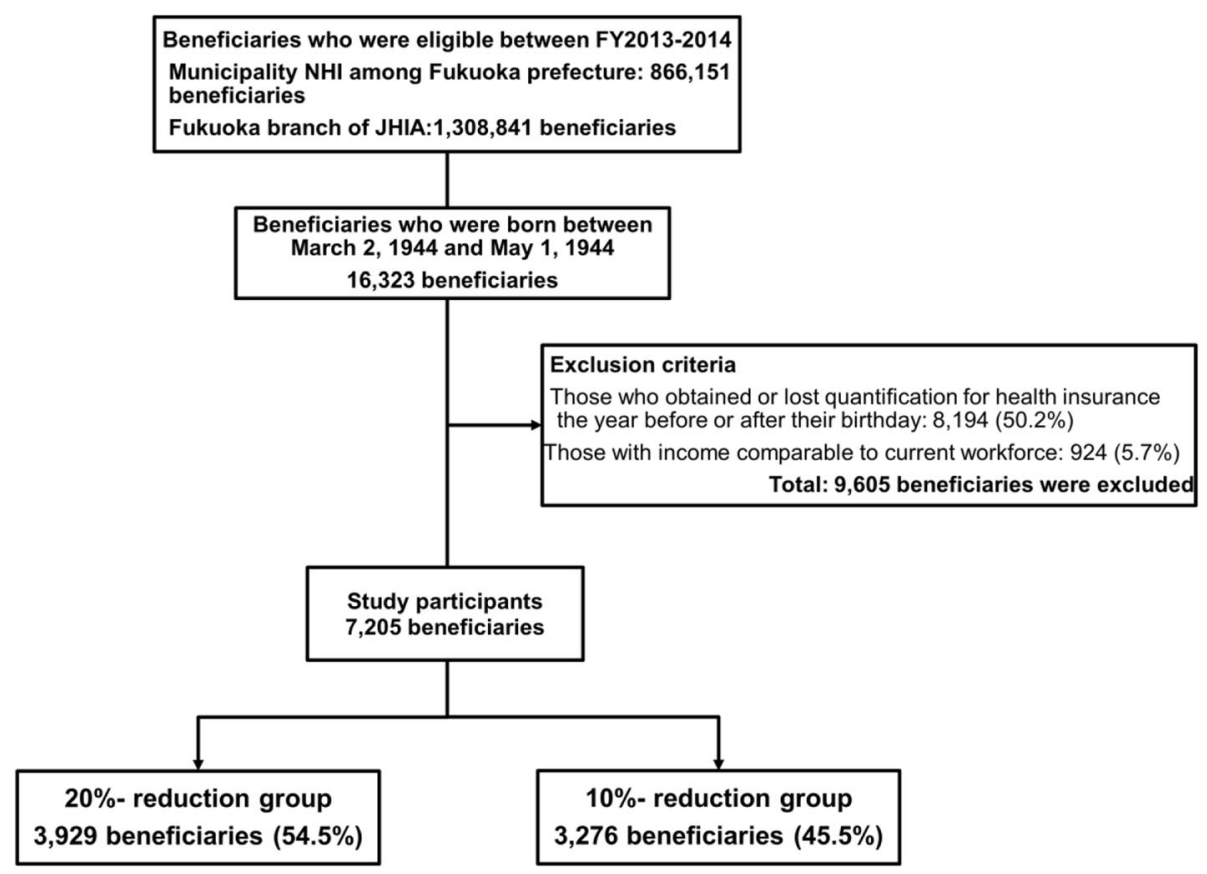

Fig. 1 Flowchart of inclusion and exclusion criteria 
Table 1 The amounts of catastrophic coverage

\begin{tabular}{|c|c|c|}
\hline & Average annual income & Catastrophic coverage: maximum out-of-pocket expenditure per month (yen) \\
\hline \multirow[t]{6}{*}{ Aged under 70 years } & Over approximately $11,600,000$ yen & $252,600+($ medical expenditure $-842,000) \times 1 \%$ \\
\hline & About $7,700,000$ to $11,600,000$ yen & $167,400+($ medical expenditure $-558,000) \times 1 \%$ \\
\hline & About $3,700,000$ to $7,700,000$ yen & $80,100+($ medical expenditure $-267,000) \times 1 \%$ \\
\hline & Under approximately $3,760,000$ yen & 57,600 \\
\hline & Exempted from residence tax & 35,400 \\
\hline & Income levels & Outpatient \\
\hline \multirow[t]{4}{*}{ Aged 70 to 74 years } & $\begin{array}{l}\text { High income } \\
\text { (Comparable to current workforce) }\end{array}$ & $80,100+($ medical expenditure $-267,000) \times 1 \%$ \\
\hline & Regular income & 44,400 \\
\hline & $\begin{array}{l}\text { Low income } \| \\
\text { (Exempt from residence tax) }\end{array}$ & 24,600 \\
\hline & $\begin{array}{l}\text { Low income I } \\
\text { (Particularly low income) }\end{array}$ & 15,000 \\
\hline
\end{tabular}

6.5\% for inpatient care. We used the 2010 exchange rate (US $\$ 1=87.75$ yen) for easy comparison with the study results reported by Fukushima et al. [7].

We employed medical expenditure and the number of outpatient visits or the length of inpatient stay as the main outcome variables. These variables were also separately measured according to inpatient and outpatient settings.

Descriptive statistics of the study subjects are shown in Table 2. The gender proportions and types of health insurance were similar between the two groups. The $20 \%$ reduction group had higher healthcare expenditure during the 2-year study period (approximately \$963.2) than the $10 \%$ group. Similarly, a difference in the number of outpatient visits was observed (approximately 3.2 days).

\section{Methods}

We assigned the $10 \%$ reduction group as the control group (reference) and the 20\% reduction group as the assigned treatment group. Thereafter, as conventional regression discontinuity design could not estimate the difference in multiple groups, the ITSA for multiple groups was employed to compare healthcare resource utilization trends before and after intervention (coinsurance rate reduction at 70 years). The ITSA offers a quasi-experimental research design for observational studies [11]. The visual depiction of multiple group ITSA is presented in Fig. 2. The solid line indicates the treatment group, and the dotted line shows the control group. The ITSA model used the following equation [12]:

$$
\begin{aligned}
Y_{\mathrm{t}}= & \beta_{0}+\beta_{1} T_{t}+\beta_{2} X_{t}+\beta_{3} X_{t} T_{t}+\beta_{4} Z+\beta_{5} Z T_{t} \\
& +\beta_{6} Z X_{t}+\beta_{7} Z X_{t} T_{t}+\varepsilon_{t}
\end{aligned}
$$

where $Y_{t}$ is the outcome measure along time $t$; $T_{t}$ is a time variable based on the point when the study began; $X_{t}$ is a dummy variable indicated as 0 before and 1 after intervention; $\mathrm{Z}$ is a dummy variable for assignment to 0 , the control, or 1 , the treatment group. $\beta_{0}$ to $\beta_{3}$ represent trends in the control group as follows: $\beta_{0}$, intercept; $\beta_{1}$, slope before the intervention; $\beta_{2}$, change in the trend caused by the intervention; $\beta_{3}$, coefficient of the interaction between $X_{t}$ and $\mathrm{T}_{\mathrm{t}}$, and the slope after the intervention. $\beta_{4}$ to $\beta_{7}$ represent differences between control and treatment groups as follows: $\beta_{4}$, difference in the intercepts; $b_{5}$, difference in the slopes before the intervention; $\beta_{6}$, difference in the changes caused by the intervention; $\beta_{7}$, difference in the slopes after the intervention [12]. After individual data were organized, we generated the ITSA dataset by aggregating individual data by month. And we employed Prais regression (PraisWinsten estimation), as statistical analyses used for ITSA must account for autocorrelated data [13]. All statistical analyses were performed using Stata 15.1 for Windows (Stata Corp, College Station, TX, USA). We then used the ITSA command [13].

\section{Results}

Total healthcare resource utilization

Table 3 presents the results of the total healthcare resource utilization obtained with the ITSA. Figure 3 presents the observed and predicted values according to the treatment setting. The solid lines and filled circles indicate the treatment group (20\% reduction group), while the dotted lines and open circles show the control group: $10 \%$ reduction group.

The $10 \%$ coinsurance rate reduction led to a significant increase in healthcare expenditure: the coefficient $\left(\beta_{2}\right)$ representing the change in the trend caused by the coinsurance rate reduction in the $10 \%$ reduction group was $71.73(P=0.001)$. And there was a 
Table 2 Descriptive statistics of study subjects

\begin{tabular}{|c|c|c|c|c|}
\hline \multirow{5}{*}{$\begin{array}{l}\text { Gender, N (\%) } \\
\end{array}$} & \multicolumn{4}{|c|}{ Coinsurance rates change } \\
\hline & \multicolumn{2}{|c|}{$20 \%$ reduction } & \multicolumn{2}{|c|}{$10 \%$ reduction } \\
\hline & \multicolumn{2}{|c|}{$(N=3929)$} & \multicolumn{2}{|c|}{$(N=3276)$} \\
\hline & & & & \\
\hline & 1779 & $(45.3 \%)$ & 1420 & $(43.3 \%)$ \\
\hline Female & 2150 & $(54.7 \%)$ & 1856 & $(56.7 \%)$ \\
\hline \multicolumn{5}{|l|}{ Type of health insurance, $N(\%)$} \\
\hline$J H I A$ & 454 & $(11.6 \%)$ & 407 & $(12.4 \%)$ \\
\hline $\mathrm{NHI}$ & 3475 & $(88.4 \%)$ & 2869 & $(87.6 \%)$ \\
\hline \multicolumn{5}{|c|}{ Healthcare resource utilization in all settings } \\
\hline \multicolumn{5}{|l|}{ Healthcare expenditure, mean (sd) } \\
\hline Before reaching 70 years old & 4255.0 & $(9168.0)$ & 3664.4 & $(7178.2)$ \\
\hline After reaching 70 years old & 5225.9 & $(10,388.0)$ & 4853.2 & $(9751.7)$ \\
\hline Overall & 9480.9 & $(16,631.8)$ & 8517.7 & $(14,773.5)$ \\
\hline Healthcare expenditure $>0$ & 3669 & $(93.4 \%)$ & 3050 & $(93.1 \%)$ \\
\hline \multicolumn{5}{|c|}{ Treatment days (No. of ambulatory visit/ length of inpatient stay), mean (sd) } \\
\hline Before reaching 70 years old & 23.4 & $(36.8)$ & 22.3 & $(35.9)$ \\
\hline After reaching 70 years old & 28.8 & $(41.8)$ & 26.3 & $(40.1)$ \\
\hline Overall & 52.2 & $(73.7)$ & 48.6 & $(72.1)$ \\
\hline \multicolumn{5}{|c|}{ Healthcare resource utilization for outpatient care } \\
\hline \multicolumn{5}{|l|}{ Healthcare expenditure, mean (sd) } \\
\hline Before reaching 70 years old & 2448.6 & $(3116.3)$ & 2426.6 & $(3220.2)$ \\
\hline After reaching 70 years old & 3018.4 & $(3590.0)$ & 2770.7 & $(3663.1)$ \\
\hline Overall & 5467.0 & $(6257.2)$ & 5197.3 & $(6590.4)$ \\
\hline Outpatient expenditure $>0$ & 3661 & $(93.2 \%)$ & 3036 & $(92.7 \%)$ \\
\hline \multicolumn{5}{|l|}{ No. of ambulatory visit, mean (sd) } \\
\hline Before reaching 70 years old & 19.0 & (24.6) & 18.4 & $(22.1)$ \\
\hline After reaching 70 years old & 23.3 & $(28.7)$ & 20.8 & $(24.0)$ \\
\hline Overall & 42.4 & $(49.6)$ & 39.2 & $(43.1)$ \\
\hline \multicolumn{5}{|c|}{ Healthcare resource utilization for inpatient care } \\
\hline \multicolumn{5}{|l|}{ Healthcare expenditure, mean (sd) } \\
\hline Before reaching 70 years old & 1806.4 & (8180.6) & 1237.9 & $(6113.4)$ \\
\hline After reaching 70 years old & 2207.5 & $(9252.3)$ & 2082.5 & $(8623.4)$ \\
\hline Overall & 4014 & $(14,381.7)$ & 3320 & $(12,487.0)$ \\
\hline Inpatient expenditure $>0$ & 860 & $(21.9 \%)$ & 664 & $(20.3 \%)$ \\
\hline \multicolumn{5}{|c|}{ No. of admission, mean(sd) } \\
\hline Before reaching to 70 years old & 0.2 & $(0.5)$ & 0.1 & $(0.4)$ \\
\hline After reaching to 70 years old & 0.2 & $(0.7)$ & 0.2 & (0.6) \\
\hline Overall & 0.4 & $(1.0)$ & 0.3 & $(0.8)$ \\
\hline \multicolumn{5}{|l|}{ Length of inpatient stay, mean (sd) } \\
\hline Before reaching 70 years old & 4.4 & $(26.8)$ & 3.9 & $(28.9)$ \\
\hline After reaching 70 years old & 9.8 & (53.6) & 9.4 & $(59.0)$ \\
\hline Overall & 5.5 & (30.3) & 5.5 & (32.6) \\
\hline
\end{tabular}

NHI National Health Insurance, JHIA Japanese Health Insurance Association

significant increase in treatment days: $\beta_{2}$ was 0.31 $(P<0.001)$. However, the coefficient $\left(\beta_{6}\right)$ representing the difference in the changes in the trend among coinsurance rate reductions was $-47.65(P=0.102)$ in healthcare expenditure and treatment days $\left(\beta_{6}\right)$ was $0.10(P=0.200)$. 


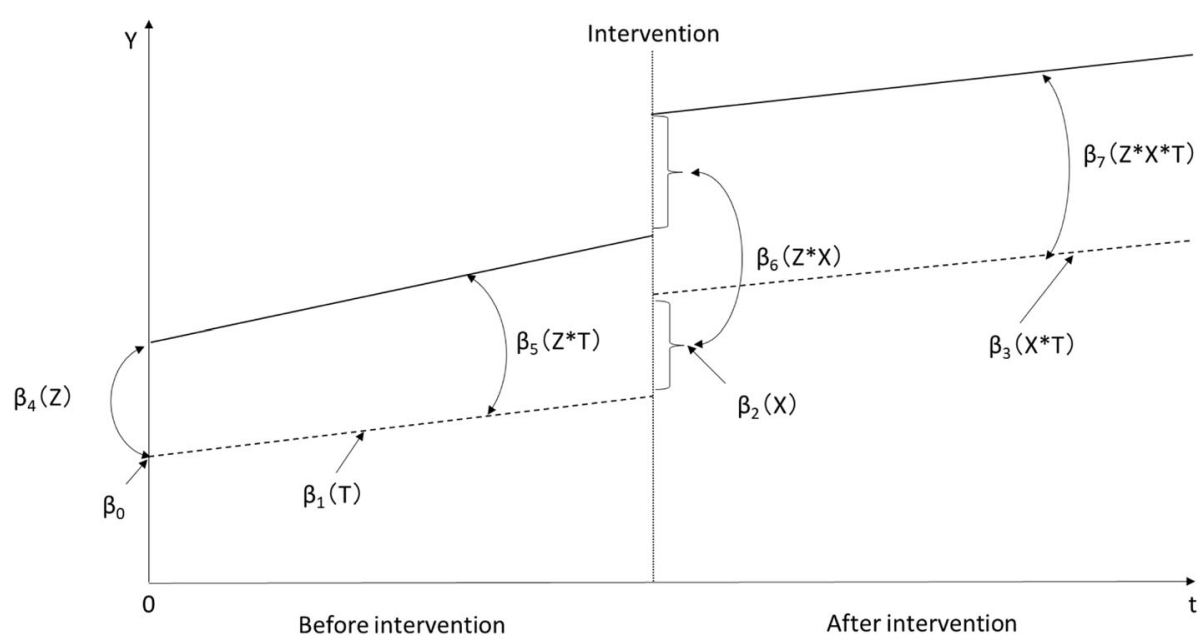

Fig. 2 Visual depiction of multiple group ITSA

Healthcare resource utilization for outpatient care Table 4 and Fig. 4 show the results of healthcare resource utilization for outpatient care obtained with the ITSA. The $10 \%$ coinsurance rate reduction led to a significant increase in healthcare expenditure for outpatient care: $\beta_{2}$ was $14.62(P=0.018)$. The $20 \%$ reduction group showed a significantly sharper increase in healthcare expenditure for outpatient care than the $10 \%$ reduction group; $\beta_{6}$ was $21.87(P=0.013)$. Similarly, the $10 \%$ coinsurance group significantly increased in the number of ambulatory visits: $\beta_{2}$ was $0.23(P<0.001)$. The $20 \%$ coinsurance rate reduction group had more frequent ambulatory care visits than the $10 \%$ reduction group: $\beta_{6}$ was $0.15(P=0.019)$.

\section{Healthcare resource utilization for inpatients care}

Table 5 and Fig. 5 show the results of healthcare resource utilization for inpatient care obtained with the

Table 3 Results for healthcare resource utilization by ITSA

\begin{tabular}{|c|c|c|c|c|c|}
\hline \multirow[b]{4}{*}{$\beta_{0}:$} & \multirow[b]{4}{*}{ Intercept } & \multicolumn{4}{|l|}{ Coeff. } \\
\hline & & \multicolumn{4}{|c|}{ (Std.err) } \\
\hline & & \multicolumn{2}{|c|}{ Expenditures } & \multicolumn{2}{|c|}{ Treatment days } \\
\hline & & 298.60 & $* * *$ & 1.85 & *** \\
\hline & & $(12.20)$ & & $(0.04)$ & \\
\hline \multirow[t]{2}{*}{$\beta_{1}:$} & Trend before the $10 \%$ coinsurance rate reduction & 1.15 & & 0.00 & \\
\hline & & $(1.93)$ & & $(0.01)$ & \\
\hline \multirow[t]{2}{*}{$\beta_{2}:$} & Change in the trend caused by $10 \%$ coinsurance rate reduction & 71.73 & ** & 0.31 & *** \\
\hline & & (20.58) & & $(0.07)$ & \\
\hline \multirow[t]{2}{*}{$\beta_{3}:$} & Trend after the $10 \%$ coinsurance rate reduction & 2.50 & & 0.00 & \\
\hline & & $(3.21)$ & & $(0.01)$ & \\
\hline \multirow[t]{2}{*}{$\beta_{4}:$} & Difference in the intercepts & 37.21 & ** & 0.12 & ** \\
\hline & & $(18.35)$ & & $(0.05)$ & \\
\hline \multirow[t]{2}{*}{$\beta_{5}:$} & Difference in the slopes before the coinsurance rate reductions & 2.26 & & 0.00 & \\
\hline & & $(2.72)$ & & $(0.01)$ & \\
\hline \multirow[t]{2}{*}{$\beta_{6}:$} & Difference in the changes in the trend caused by coinsurance rate reductions & -47.65 & & 0.10 & \\
\hline & & $(28.51)$ & & $(0.08)$ & \\
\hline \multirow[t]{4}{*}{$\beta_{7}:$} & Difference in the slopes after the coinsurance rate reductions & 0.31 & & 0.01 & \\
\hline & & $(4.21)$ & & $(0.01)$ & \\
\hline & $\mathrm{R}^{2}$ & 0.85 & & 0.92 & \\
\hline & Observations & 48 & & 48 & \\
\hline
\end{tabular}

${ }^{* * *} p<0.001,{ }^{* * *} p<0.05,{ }^{*} p<0.1$ 


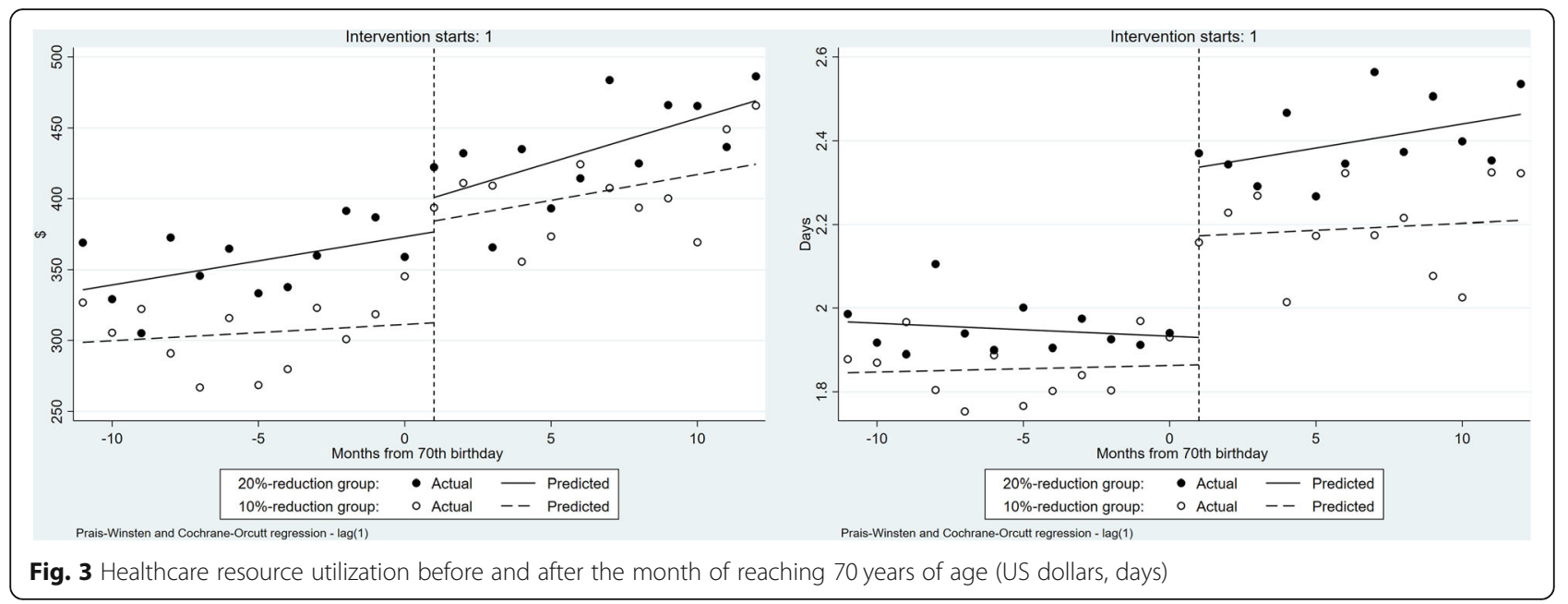

ITSA. The $10 \%$ coinsurance rate reduction led to an increase in inpatient healthcare resource utilization: $\beta_{2}$ was 55.72 for expenditure $(P=0.005)$ and 0.06 $(P=0.065)$ for length of inpatient stay. In addition, the $20 \%$ reduction group tended to have fewer changes in inpatient expenditure than the $10 \%$ reduction group: $\beta_{6}$ was $-69.05(P=0.011)$, while no significant differences was found in the length of inpatient stay among coinsurance rate reduction groups.

\section{Discussion}

We found that a $10 \%$ coinsurance rate reduction also tended to increase the utilization of outpatient healthcare resources. When comparing 10\% coinsurance rate

Table 4 Results for healthcare resource utilization for outpatient care by ITSA

\begin{tabular}{|c|c|c|c|c|c|}
\hline & & Coeff. & & & \\
\hline & & (Std.err & & & \\
\hline & & $\overline{\text { Expend }}$ & & No. o & y visit \\
\hline$\overline{\beta_{0}}:$ & Intercept & 200.56 & $* * *$ & 1.56 & *** \\
\hline & & $(2.80)$ & & $(0.02)$ & \\
\hline$\beta_{1}:$ & Trend before the $10 \%$ coinsurance rates reduction & 0.31 & & -0.01 & \\
\hline & & $(0.38)$ & & $(0.00)$ & \\
\hline$\beta_{2}:$ & Change in the trend caused by $10 \%$ coinsurance rates reduction & 14.62 & ** & 0.23 & $* * *$ \\
\hline & & $(5.91)$ & & $(0.05)$ & \\
\hline$\beta_{3}:$ & Trend after the $10 \%$ coinsurance rates reduction & 1.74 & & 0.01 & \\
\hline & & $(1.16)$ & & $(0.01)$ & \\
\hline$\beta_{4}:$ & Difference in the intercepts & 5.07 & & 0.07 & $* *$ \\
\hline & & $(3.47)$ & & $(0.03)$ & \\
\hline$\beta_{5}:$ & Difference in the slopes before the coinsurance rate reductions & -0.54 & & 0.00 & \\
\hline & & $(0.54)$ & & $(0.01)$ & \\
\hline$\beta_{6}:$ & Difference in the changes in the trend caused by coinsurance rate reductions & 21.87 & $* *$ & 0.15 & ** \\
\hline & & $(8.46)$ & & $(0.06)$ & \\
\hline$\beta_{7}:$ & Difference in the slopes after the coinsurance rate reductions & 0.56 & & 0.01 & \\
\hline & & $(1.51)$ & & $(0.01)$ & \\
\hline & $\mathrm{R}^{2}$ & 0.92 & & 0.91 & \\
\hline & Observations & 48 & & 48 & \\
\hline
\end{tabular}

${ }^{* * *} p<0.001,{ }^{* * *} p<0.05,{ }^{*} p<0.1$ 

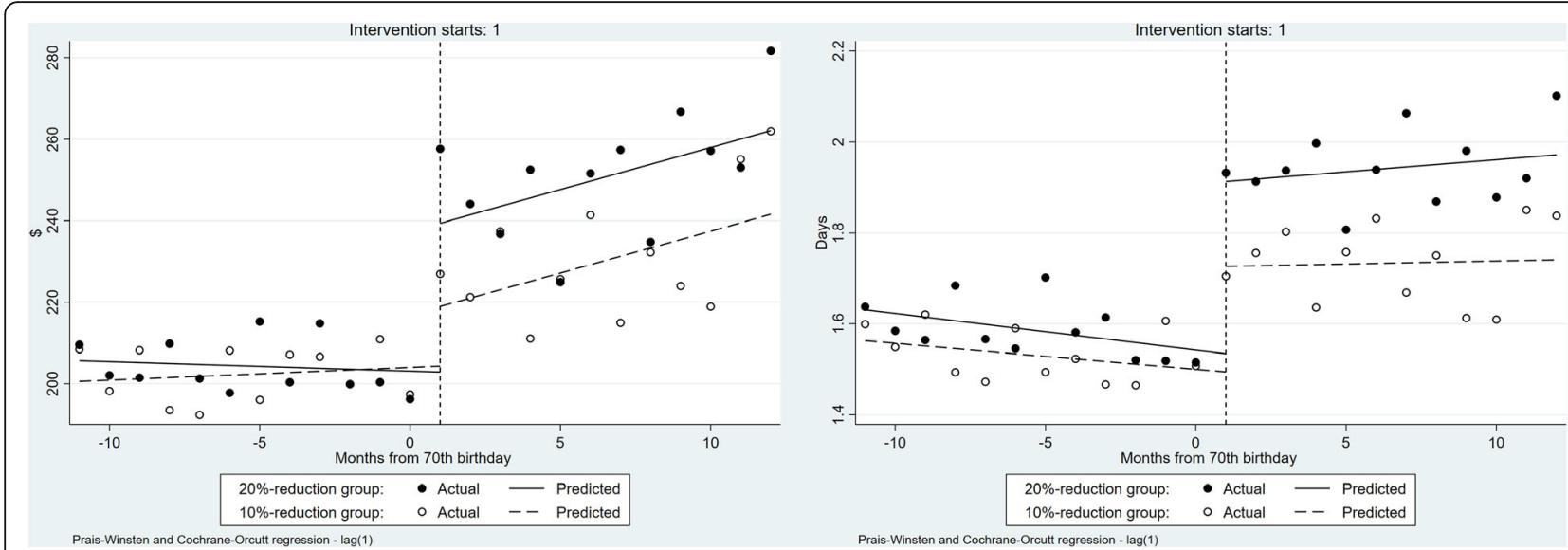

Fig. 4 Healthcare resource utilization for outpatient care before and after the month of reaching 70 years of age

reduction with that of $20 \%$, the increases in health care resource utilization was larger for the $20 \%$ reduction group than the $10 \%$ reduction group, particularly in the outpatient setting. Unlike previous investigations, the present study evaluated not only the effects of decreased coinsurance at age 70 on healthcare resource utilization under the revised coinsurance rate but also examined differences in the period before and after coinsurance rate revision. Substantial increases and differences among coinsurance rate groups were evident only in outpatient healthcare resource utilization immediately after the age of 70 . These results were consistent with those of a previous study [7]. However, Shigeoka reported a clear effect of the reduction in inpatient admission after individuals were 70 years old [6]. These inconsistent results could be because of the difference in study design and data whether longitudinal claims data or repeated cross-sectional survey data were used.

Table 5 Results for healthcare resource utilization for inpatient care by ITSA

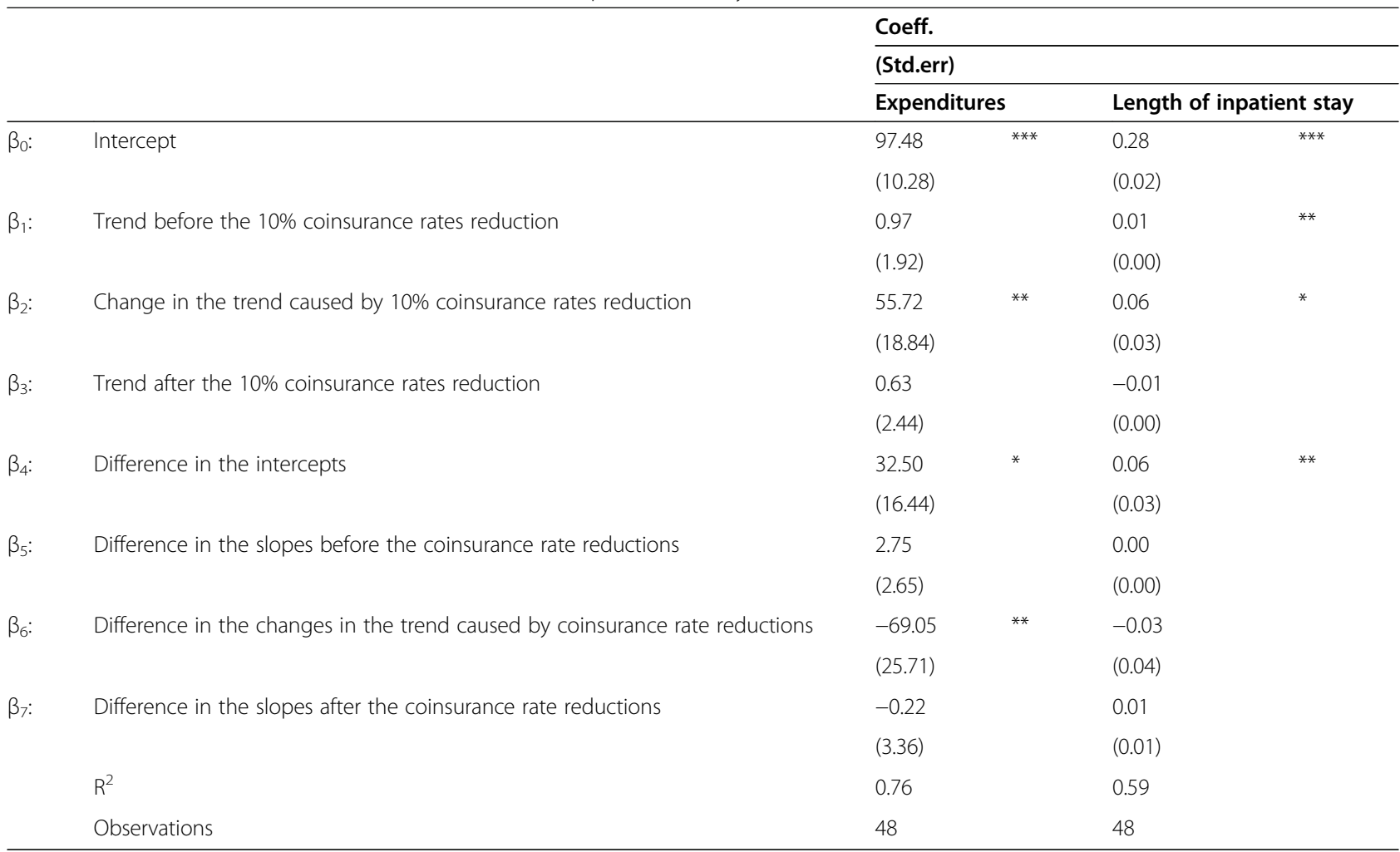

${ }^{* * *} p<0.001,{ }^{* * *} p<0.05,{ }^{*} p<0.1$ 


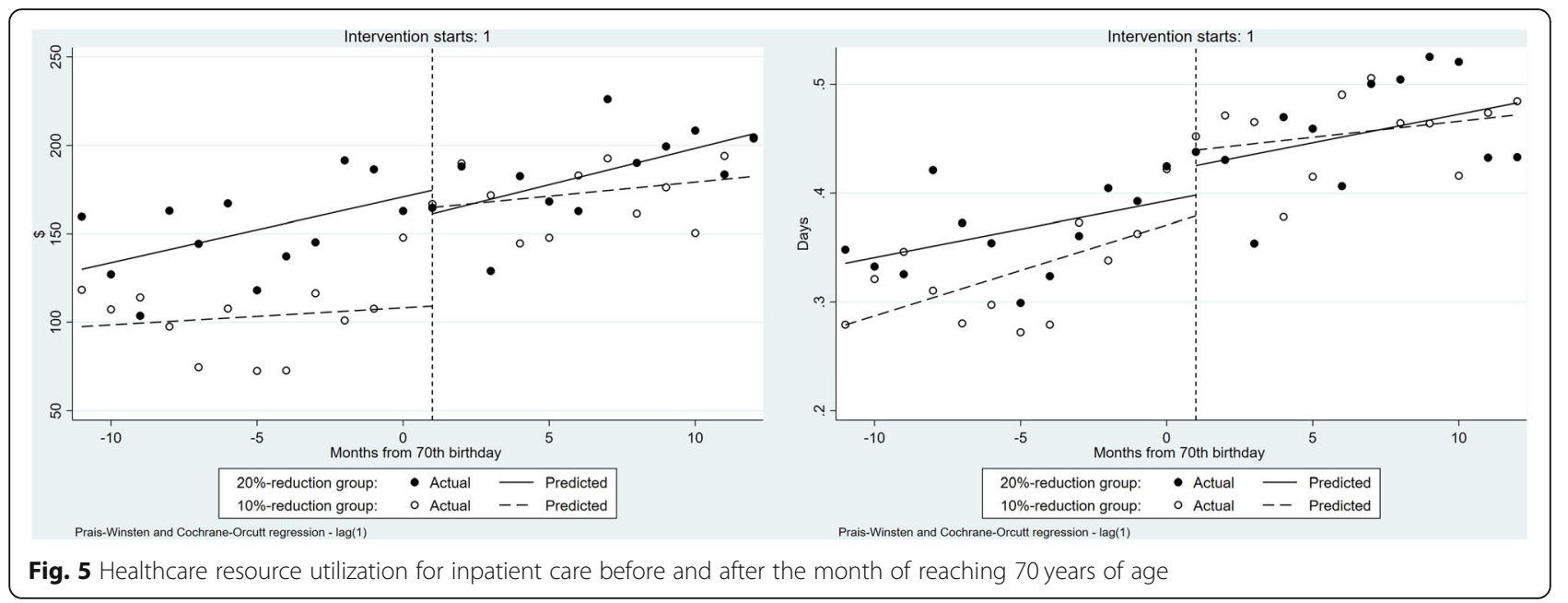

Moreover, conditions demanding inpatient care are severe or critical, and although we removed beneficiaries who died during the study period, some results for inpatient healthcare resource utilization were unclear. This is especially true in more expensive inpatient care, as the municipality NHI was the insurer for most of the people aged 65-74 years, this study's subjects would be less healthy than that of the previous study. Indeed, compared with the probability of Fukushima et al., which was 0.652 and 0.0187 per person-month for outpatient and inpatient care, respectively, the proportion of our study subjects who visited ambulatory care at least once during the study period was $92.9 \%$ and that of those hospitalized was $21.2 \%$. Additionally, the higher coinsurance rates are, the more applicable the catastrophic coverage becomes, because the $10 \%$ reduction group tended to reach the threshold of healthcare expenditure and the effect of coinsurance rate revision could be offset by the effect of out-of-pocket caps in expensive treatment. (in outpatients care; $10 \%$ coinsurance rate: 120,000 yen vs $20 \%$ coinsurance rate: 60,000 yen, in inpatient care; 444 , 000 yen vs 222,000 yen). Therefore, as we did not exclude the participants who received catastrophic coverage, the counteracted effect could nave led to unclear result related to inpatient healthcare resource utilization which tended to be more expensive than outpatient care.

Further, patients would postpone outpatient care, which would be deferred, as they knew that their coinsurance rates decreased at 70 years of age. Recently, Lin and Sacks reported that subjects in deductible plans increased spending and utilization to hit the maximum dollar expenditure in the last 3 months of every coverage year, and those in free care also increased at the end of the experiment year, except for acute care, by analyzing the data from the RAND Health Insurance Experiment
[14]. Their results provided strong evidence of intertemporal substitution. Thus, our results imply that outpatient healthcare resource before and after 70 years of age would be affected by intertemporal substitution.

However, this study has several limitations. First, the sample size of this study was smaller than that of previous reports. Thus, sub-analyses, such as stratified analyses by clinical departments, could not be performed. Second, as observation periods in this study were shorter than those in previous investigations, our study subjects did not tend to hospitalize. Third, there may still remain selection bias because our data included beneficiaries only in a Fukuoka prefecture. Moreover, our data did not include beneficiaries of health insurance societies and mutual-aid associations. The total population aged 70-74 years in Fukuoka prefecture was 292,231 on April 1st, 2015 [15], and the number of beneficiaries older than 70 years were 216,243 in municipality NHI in Fukuoka prefecture and 15,714 in the Fukuoka branch of JHIA at the end of FY 2014 [16, 17]. Thus, our data covered at least $79.3 \%$ of the total population, although we could not collect information about the number of older adults receiving public assistance who were not covered by health insurance. Therefore, further research should be conducted to reveal the long-term effects of coinsurance rates revision. Additionally, public and political concerns about coinsurance rate revision for those older than 75 years has recently been growing; however, insurers for this age group are independent of other insurers. In this study, we developed a longitudinal database including long-term care insurance claims and health check-ups data, enabling us to investigate the long-term effect of the coinsurance rate revision throughout various insurers. Thus, we could examine the effects of coinsurance rate reduction for the $10 \%$ 
reduction group at 75 years on health status and longterm care resource utilization in the near future, after the beneficiaries who were born after April 2, 1944 reached 75 years of age in FY2019.

\section{Conclusion}

In this study, we estimated the economic impacts of the 2014 coinsurance rate revision on healthcare resource utilization in Japan. We analyzed longitudinal health insurance claims data of municipality NHI in Fukuoka Prefecture and the Fukuoka branch of the JHIA by using ITSA. As a result, we found that the coinsurance reduction from 30 to $20 \%$ also had an impact on the outpatient healthcare resources utilization. Further, we observed that the impact was smaller than with a $20 \%$ reduction in outpatient care resource utilization, while it was larger for inpatient healthcare expenditure.

Our results provide the new finding that substantial increases and differences caused by coinsurance rate revision were evident only in outpatient healthcare resource utilization. Further, our findings contribute to the policy debates for cost sharing by elderly people in Japan. In conclusion, we clarified that increasing the coinsurance rate among the elderly in Japan would reduce outpatient healthcare resource utilization; however, it would not necessarily reduce overall healthcare resource utilization.

\section{Abbreviations}

FY: Fiscal year; NHI: National health insurance; ITSA: Interrupted time-series analysis; JHIA: Japanese health insurance association; DPC/PDPS: Diagnosis procedure combination per diem payment system

\section{Acknowledgments}

We express our gratitude to municipalities in Fukuoka Prefecture and the Fukuoka branch of the Japanese Health Insurance Association for the provision of valuable data. We greatly appreciate Dr. Toshiaki lizuka at the Japan Economic Association 2019 Spring meeting for his helpful comments.

\section{Authors' contributions}

TN conducted literature searches, reviewed articles, synthesized findings, and drafted the manuscript. TM, SK, and AB contributed to data synthesis and manuscript preparation. All authors read and approved the final manuscript.

\section{Funding}

This study was supported by JSPS KAKENHI (Grant Number 17 K15873; 19H03879).

\section{Availability of data and materials}

We cannot make our data publicly available because the insurers did not provide permission to do so.

\section{Declarations}

\section{Ethics approval and consent to participate}

The need for informed consent for this study was waived according to the Ethical Guidelines for Medical and Health Research Involving Human Subjects in Japan. This was because the study used a retrospective cohort, and analyzed data were anonymized. This study was approved by the Ethics Committee of Life Science, Fukuoka Institute of Health and Environmental Sciences (No. 30-6), and Kyushu University Institutional Review Board for Clinical Research (No. 28-84).
Consent for publication

Not applicable.

\section{Competing interests}

The authors declare that they have no competing interests.

\section{Author details}

'Department of Research Planning and Information Management, Fukuoka Institute of Health and Environmental Sciences, 39 Mukaizano, Dazaifu-shi, Fukuoka 818-0135, Japan. ${ }^{2}$ Department of Public Health and Preventive Medicine, Fukuoka University, Fukuoka, Japan. ${ }^{3}$ Department of Health Care Administration and Management, Graduate School of Medical Sciences, Kyushu University, Fukuoka, Japan.

Received: 26 April 2021 Accepted: 26 June 2021

Published online: 06 July 2021

\section{References}

1. Ministry of Internal Affairs and Communications, Japan. Population statistics of Japanese elderly people age 65 years old and over. 2020. https://www. stat.go.jp/data/topics/pdf/topics126.pdf (in Japanese). Retrieved January 19, 2021.

2. Cabinet Secretariat, Cabinet Office, Ministry of Finance, Ministry of Health, Labour and Welfare. Future outlook for social security in anticipation of 2040 (material for discussion). https://www.mhlw.go.jp/file/06-Seisa kujouhou-12600000-Seisakutoukatsukan/0000207398.pdf (in Japanese). Retrieved June 16, 2021.

3. Manning WG, Newhouse JP, Duan N, Keeler EB, Leibowitz A. Health insurance and the demand for medical care: evidence from a randomized experiment. Am Econ Rev. 1987;77(3):251-77.

4. Chandra A, Gruber J, McKnight R. Patient cost-sharing and hospitalization offsets in the elderly. Am Econ Rev. 2010;100(1):193-213. https://doi.org/1 0.1257/aer.100.1.193

5. Ministry of Health, Labour and Welfare. Estimates of National Medical Care Expenditure, FY 2017. 2019. https://www.mhlw.go.jp/english/database/dbhss/dl/digest2017.pdf. Retrieved January 19, 2021.

6. Shigeoka $\mathrm{H}$. The effect of patient cost sharing on utilization, health, and risk protection. Am Econ Rev. 2014;104(7):2152-84. https://doi.org/10.1257/aer.1 04.7.2152

7. Fukushima K, Mizuoka S, Yamamoto S, lizuka T. Patient cost sharing and medical expenditures for the elderly. J Health Econ. 2016;45:115-30. https:// doi.org/10.1016/j.jhealeco.2015.10.005.

8. Mahlich J, Sruamsiri R. Co-insurance and health care utilization in Japanese patients with rheumatoid arthritis: a discontinuity regression approach. J Equity Health. 2019;18(1):22. https://doi.org/10.1186/s12939-019-0920-7.

9. Ministry of Health, Labour and Welfare. (Amendment of Act No. 28 of 2012). National Health Insurance Act. 1958. http://www.japaneselawtranslation.go. $\mathrm{jp} / \mathrm{law} /$ detail/?ft $=5 \& \mathrm{re}=02 \& \mathrm{dn}=1 \& \mathrm{gn}=3 \& \mathrm{sy}=33 \& \mathrm{ht}=\mathrm{A} \& n o=192 \& \mathrm{x}=53 \& \mathrm{y}=$ $1 \& i a=03 \& j a=04 \& k y=\& p a g e=1$. Retrieved January 19, 2021.

10. Ministry of Health, Labour and Welfare. (Amendment of Act No. 31 of 2015). Health Insurance Act. 1922. http://www.japaneselawtranslation.go.jp/law/ detail/?ft $=5 \&$ re $=02 \& d n=1 \& g n=2 \&$ sy $=11 \& \mathrm{ht}=\mathrm{A} \& \mathrm{no}=70 \& \mathrm{x}=21 \& \mathrm{y}=18 \& \mathrm{ia}=03$ $\& j a=04 \& k y=\&$ page $=1$ Retrieved January 19, 2021.

11. Kontopantelis E, Doran T, Springate DA, Buchan I, Reeves D. Regression based quasi-experimental approach when randomisation is not an option: interrupted time series analysis. BMJ. 2015;350:h2750. https://doi.org/10.113 6/bmj.h2750.

12. Linden A, Adams J. Applying a propensity-score based weighting model to interrupted time series data: improving causal inference in program evaluation. J Eval Clin Pract. 2011;17:1231-8. https://doi.org/10.1111/j.1365-2 753.2010.01504.x.

13. Linden A, Arbor A. Conducting interrupted time series analysis for single and multiple group comparisons. Stata J. 2015;15:480-500 https://doi.org/1 $0.1177 / 1536867 \times 1501500208$.

14. Lin H, Sacks D. Intertemporal substitution in health care demand: evidence from the RAND health insurance experiment. J Public Econ. 2019;175:29-43. https://doi.org/10.1016/j.jpubeco.2019.04.006.

15. Fukuoka city government, municipality OPEN DATA; Annual Population and Social Security Surveys April 1st 2015. https://ckan.open-governmentdata. org/dataset/f3149440-e9cf-43ca-b9fa-09e4773d6d27/resource/55975471- 
e9bc-45b1-8157-416c7101d294/download/9131.xls (in Japanese). Retrieved April 12, 2021.

16. Japanese Health Insurance Association. Business annual report. 2014. https:// www.kyoukaikenpo.or.jp/ /media/Files/honbu/cat740/2804/406/160405010. xIsx (in Japanese). Retrieved April 12, 2021.

17. Fukuoka prefectural government, Annual report of the status of the National Health Insurance in Fukuoka Prefecture (FY2014). https://www.pref. fukuoka.lg.jp/uploaded/life/257191_52506889_misc.pdf (in Japanese). Retrieved April 12, 2021

\section{Publisher's Note}

Springer Nature remains neutral with regard to jurisdictional claims in published maps and institutional affiliations.

Ready to submit your research? Choose BMC and benefit from:

- fast, convenient online submission

- thorough peer review by experienced researchers in your field

- rapid publication on acceptance

- support for research data, including large and complex data types

- gold Open Access which fosters wider collaboration and increased citations

- maximum visibility for your research: over $100 \mathrm{M}$ website views per year

At $\mathrm{BMC}$, research is always in progress.

Learn more biomedcentral.com/submissions 